\title{
Field-Observed Cracking of Paired Lightweight and Normalweight Concrete Bridge Decks
}

\author{
Tara L. Cavalline $^{1), *}\left(\mathbb{D}\right.$, Jeremy T. Calamusa ${ }^{2)}$, Amy M. Kitts $^{3)}$, and Brett Q. Tempest ${ }^{4)}$
}

(Received July 7, 2016, Accepted October 18, 2016, Published online February 16, 2017)

\begin{abstract}
Research has suggested that conventional lightweight concrete can offer durability advantages due to reduced cracking tendency. Although a number of publications exist providing the results of laboratory-based studies on the durability performance of lightweight concrete (with lightweight coarse aggregate) and internally cured concrete (using prewetted lightweight fine aggregate), far fewer field studies of durability performance of conventional lightweight concrete bridge decks in service have been performed. This study was commissioned to provide insight to a highway agency on whether enhanced durability performance, and therefore reduced maintenance and longer lifecycles, could be anticipated from existing lightweight concrete bridge decks that were not intentionally internally cured. To facilitate performance comparison, each lightweight bridge deck selected for inclusion in this study was paired with a companion normalweight bridge deck on a bridge of similar structural type, deck thickness, and geometric configuration, with similar age, traffic, and environmental exposure. The field-observed cracking of the decks was recorded and evaluated, and crack densities for transverse, longitudinal, and pattern cracking of the normalweight and lightweight deck in each pair were compared. Although some trends linking crack prevalence to geographic location, traffic, and age were observed, a distinct difference between the cracking present in the paired lightweight and normalweight bridge decks included in this study was not readily evident. Statistical analysis using analysis of covariance (ANCOVA) to adjust for age and traffic influence did not indicate that the type of concrete deck (lightweight or normalweight) is a statistically significant factor in the observed cracking. Therefore, for these service environments, lightweight decks did not consistently demonstrate reduced cracking.
\end{abstract}

Keywords: lightweight concrete, bridge decks, cracking, durability, field study.

\section{Introduction}

Cracks provide a means for accelerated ingress of chlorides and other aggressive contaminants into concrete, causing corrosion of the reinforcing steel and other degradation of the concrete. Damage due to corrosion causes reduction in strength, serviceability, and aesthetics of the structure (Chini et al. 2003), and surface scaling and spalling due to freeze-thaw action is also worsened by presence of cracks (Reinhardt 2008).

\footnotetext{
${ }^{1)}$ Department of Engineering Technology and Construction Management, University of North Carolina at Charlotte, 9201 University City Boulevard, Charlotte, NC 28223, USA.

*Corresponding Author; E-mail: tcavalline@uncc.edu

${ }^{2)}$ The Whiting-Turner Construction Company, 800 West Hill Street Suite 400, Charlotte, NC 28208, USA.

${ }^{3)}$ Department of Engineering Technology, Old Dominion University, 102 Kaufman Hall, Norfolk, VA 23529, USA.

${ }^{4)}$ Department of Civil and Environmental Engineering, University of North Carolina at Charlotte, 9201

University City Boulevard, Charlotte, NC 28223, USA.

Copyright $($ The Author(s) 2017. This article is published with open access at Springerlink.com
}

Therefore, controlling and reducing cracks in concrete bridge decks is paramount to durability performance. The enhanced durability of concrete internally cured using prewetted lightweight fine aggregate has been documented by a number of research studies (Bentur et al. 2001; Geiker et al. 2004; Hammer et al. 2004; Delatte et al. 2007b; Bentz and Weiss 2011), and a growing number of highway agencies are moving towards field implementation of internally cured bridge decks using prewetted lightweight fine aggregates (Streeter 2012; Guthrie and Yaede 2013; Barrett et al. 2013; Jones et al. 2014). However, many existing bridge decks have been constructed utilizing conventional lightweight concrete containing lightweight coarse aggregates, mixtures not specifically designed for internal curing. Therefore, the relative durability performance of these decks, compared to normalweight decks of similar ages and in similar service conditions, is of interest to many highway agencies to aid in prediction of performance over the remaining service life and in budgeting and forecasting for future repair, rehabilitation, and ultimately replacement.

Research suggests that lightweight concrete, even if not intentionally internally cured using a suitable quantity of prewetted fine lightweight aggregate, can provide substantial advantages over normalweight concrete in a number of applications, including bridge decks (Vaysburd 1996; Harmon 2005). It has been suggested that these advantages 
extend beyond reduced self-weight, and include enhanced durability performance associated with reduced permeability and reduced cracking tendency (Delatte et al. 2007b). Many of these benefits could be linked to the fact that often coarse lightweight aggregates are introduced to the concrete mixture in a prewetted state. The improved contact zone between aggregate and cement paste, internal curing effects, and the reduced modulus of elasticity are touted as possible contributors to the enhanced durability performance of lightweight concrete (Vaysburd 1996; Ramirez et al. 2000; Wolfe 2008 and others). Some research has shown that lightweight concrete can have lower levels of microcracking as well as higher resistance to weathering and corrosion (Reinhardt 2008). Use of lightweight concrete in bridge decks has, however, caused some durability concerns for practitioners. These concerns include reduced resistance to salt scaling and lower abrasion resistance (Ozyildirim 2008).

Lightweight aggregate manufacturers and others have documented the field performance of lightweight concrete in some bridge deck applications, including those in severe climates in the United States (Harmon 2005; Wolfe 2008) and abroad (Harmon 2005). Wolfe (2008) describes the successful performance of a number of lightweight bridge decks in Middle Atlantic and Northeast regions of the United States, and Harmon (2005) discusses successful placement of lightweight concrete in bridges in Norway and in San Francisco. However, only a few comprehensive field studies of the durability performance of lightweight concrete bridge decks have been performed. Two studies of note in the United States included those for Ohio Department of Transportation (ODOT) and for the Federal Highway Administration (FHWA). In a field study including 116 HPC bridge decks placed between 1994 and 2001 (Crowl and Sutak 2002), Ohio Department of Transportation in the United States found that "bridges with little or no cracking used coarse aggregate with an absorption $>1 \%$, while $75 \%$ of bridges with unacceptable cracking used coarse aggregate with absorption $<1 \%$ (Delatte et al. 2007b)." However, in further study by Delatte et al. (2007b), the benefits of internal curing were far more prevalent in mixtures that utilized fine aggregate (Delatte et al. 2007b). As part of a study for the Federal Highway Administration Russell et al. (2006) compiled field performance data on 16 high performance concrete (HPC) bridge decks across the United States. Measured field data compiled for the report include a number of durability performance characteristics (freeze-thaw performance, scaling, abrasion, chloride penetration), but not assessment or quantification of cracking. Although providing guidance on specifications for lightweight decks based on project findings, detailed information on the performance of the lightweight decks is not provided.

Field studies provide insight into performance that is not readily available through laboratory based studies to aid highway agencies in performance prediction and project planning. Based on the review of literature, a limited number of field studies focused on the durability of lightweight concrete decks have been performed. Specifically, a paired field study of lightweight and normalweight bridge decks offering a direct performance comparison was not found in the literature.

\section{Background Information on Cracking in Bridge Decks}

Factors that are generally accepted to be influential in bridge deck cracking include bridge design, concrete mixture design, materials used in the concrete mixture, and construction techniques. In addition, environmental influences such as temperature and humidity also contribute to the development of stresses (TRB 2006). Most bridge deck cracks initiate in early ages (Darwin et al. 2004). These early cracks propagate over time, and additional cracks form for various reasons.

A number of factors related to bridge design can contribute to bridge deck cracking (ElSafty and Abdel Mohti 2013). Restraint is typically caused by end conditions and the composite action between the bridge deck and the supporting members of the superstructure. The fixity conditions at abutments can influence cracking in the end spans of bridge decks (Darwin et al. 2004). Restraint can also be provided by stay-in-place forms (Saadeghvaziri and Hadidi 2005). Thicker bridge decks tend to have less cracking (TRB 2006; ElSafty and Abdel-Mohti 2013), although the relative stiffnesses of the bridge deck and the girders is an important factor in the propensity for a deck to experience cracking (Hadidi and Saadeghvaziri 2005). The type of girder used in a bridge superstructure has been shown to influence cracking, with bridge decks of steel girder bridges often exhibiting more cracking than bridge decks supported by other types of girders due to stiffness (Perfetti et al. 1985; Krauss and Rogalla 1996). The type of phased construction and continuity between spans in bridges built with precast girders can have important consequences in bridge deck cracking (Sousa et al. 2012). ElSafty and Abdel-Mohti (2013) found that deflection is an important parameter affecting cracking. Reinforcing steel characteristics (including bar size, spacing, cover, and other details) can affect the extent of bridge deck cracking (Hadidi and Saadeghvaziri 2005) as well as crack widths and patterns (Soltani et al. 2013).

Research into the relationship of traffic to bridge deck cracking has provided mixed findings. Several researchers found no relationship between traffic and bridge deck cracking tendency (Stewart and Gundersonn 1969; Cady and Carrier 1971; Cady et al. 1971; Krauss and Rogalla 1996). However, a study by McKeel (1985) concluded that "bridges that carry fewer trucks at lower speeds exhibit less cracking than those that carry large number of trucks at higher speeds."

The concrete mixture used in a bridge deck can also influence cracking. Weiss et al. (1999) cites five factors that cause an increase in cracking potential with higher strength concrete mixtures. These five factors are early-age autogenous shrinkage, higher material stiffness, increased brittleness, reduced creep, and increased shrinkage rate. In light of the purpose of this study, it is noted that the use of lightweight aggregate will impact each of these five factors, particularly due to the decreased modulus of elasticity, additional curing water from prewetted lightweight 
aggregates, and potentially higher cement contents utilized to meet strength requirements (Neville 1995).

In general, concrete mixtures with higher aggregate content (and correspondingly, lower paste content) exhibit a reduced tendency to crack. This is due to reduction in the paste fraction (lowering shrinkage potential) along with an increase in the proportion of the mixture least susceptible to thermal stresses (TRB 2006). Although concrete relies on its strength to resist cracking, for bridge decks, higher compressive strength does not necessarily correlate to more resistance to cracking (Darwin et al. 2004). This is often attributed to the higher modulus of elasticity that accompanies early age strength gain, as well as the increased paste volume and hydration temperatures associated with higher cement contents (Hadidi and Saadeghvaziri 2005). During the past two decades, cement has become finer, which can also result in greater shrinkage of the concrete (Chariton and Weiss 2002). When supplementary cementitious materials (SCMs) are utilized, concrete has a reduced tendency to crack, due to lower early age temperatures and slower development of strength and elastic modulus (TRB 2006). Silica fume has been utilized in bridge deck concrete to reduce permeability, but has also been associated with early age cracking (Delatte et al. 2007a).

Since volume changes are largely attributable to the paste fraction, it is generally accepted that concrete mixtures that incorporate larger aggregate sizes experience less cracking (TRB 2006). The absorption of aggregates used in concrete "is closely related to its porosity, and the porosity influences the stiffness and compressibility (TRB 2006).” As aggregates with high absorptions tend to be more compressible, they tend to experience more volume changes due to shrinkage, with coarse aggregates tending to be more influential on the overall drying shrinkage than fine aggregates (TRB 2006). The high absorption of lightweight aggregates, however, can be used to reduce cracking due to internal curing (Neville 1995; Delatte et al. 2007b).

Practices employed during construction of a bridge deck have been implicated as a cause of (or as a contributor to) cracking of concrete. Evaporative effects caused by wind and low humidity have long been known to be a key cause of plastic shrinkage cracks, and proper curing techniques are essential to prevention of this type of cracking. Construction sequencing, including pour sequencing, can influence cracking (Hadidi and Saadeghvaziri 2005), as do vibration techniques, weight and vibration of construction equipment, and deflection of formwork (Issa 1999).

\section{Research Significance and Objectives}

The decision to utilize lightweight concrete in bridge decks is often made on the basis of the ability to reduce the dead load of the bridge deck and potentially allow for reduction in the robustness of other bridge superstructure and substructure elements. Enhanced durability performance of lightweight bridge decks could offer incentive for highway agencies to select lightweight concrete for lifecycle benefits, potentially helping to offset the increased cost of most manufactured lightweight aggregate. However, field studies directly comparing the performance of lightweight and normalweight decks in similar service environments do not exist to help support decision making. This study was commissioned to provide insight to the highway agency on whether enhanced durability performance, and therefore reduced maintenance and longer lifecycles, could be anticipated from existing lightweight bridge decks.

The work presented in this paper is a portion of a larger research program designed to evaluate the field-observed cracking of lightweight concrete bridge decks, comparing to normalweight concrete in the same structure or service environment. Full details on the findings of this larger study are presented in Cavalline et al. (2013). This paper provides detailed analysis of the results of field-observed cracking. For each lightweight concrete bridge deck selected for inclusion in this study, a companion normalweight bridge deck of similar age, traffic loading, and environmental exposure, structural type, deck thickness, and geometric configuration was selected to facilitate comparison. The influence of geographic region of the state on the relative durability performance of lightweight and normalweight concrete decks was also of interest to the state highway agency, as well as the potential influence of structural characteristics. Climatic conditions vary across North Carolina, which has three distinct regions: Mountain, Piedmont, and Coastal. Due to the diverse topography and climate in these regions, bridges across the state receive differing exposure to moisture, freeze-thaw cycles, and deicing and anti-icing agents. The decks included in the study were constructed with different types of girders (steel and precast concrete) and either the presence or absence of stay-in-place forms. Bridge pair selection was performed in a manner that allowed pairwise comparison of the two types of decks (holding age, traffic, and design/construction characteristics fairly constant), as well as identification of the potential influence of the factors such as superstructure characteristics, traffic, and age on cracking using statistical analysis.

\section{Experimental Program}

Decks selected for inclusion in this study, along with information on the geographic region of the state, year constructed, traffic information, and type of superstructure are shown in Table 1. It is noted that none of the lightweight decks were specifically designed for internal curing, and contained only lightweight coarse aggregate. None of the decks selected for this study had a superficial surface treatment (coating, topping slab or asphalt overlay). Care was taken by the state highway agency sponsoring this research to identify pairs of bridge decks that would provide very similar structural characteristics. All pairs were selected to have very similar span lengths, deck thicknesses, and geometries. For most pairs of bridges, the type of superstructure is of the same type. However, for lightweight bridge decks in the mountain regions, it was not possible to 
Table 1 Bridge decks included in the study.

\begin{tabular}{|c|c|c|c|c|c|}
\hline Region & Pair/ID & Type of deck & Year built & ADT & Superstructure \\
\hline \multirow[t]{8}{*}{ Coastal } & $1 \mathrm{~N}$ & NWC & 1998 & 4,300 & $\begin{array}{l}\text { Reinforced concrete deck on } \\
\text { prestressed concrete girders }\end{array}$ \\
\hline & $1 \mathrm{~L}$ & LWC & 2000 & 9,400 & $\begin{array}{l}\text { Reinforced concrete deck, } \\
\text { prestressed concrete panels on } \\
\text { prestressed concrete girders }\end{array}$ \\
\hline & $2 \mathrm{~N}$ & NWC & 1995 & 1,300 & $\begin{array}{l}\text { Reinforced concrete deck on } \\
\text { prestressed concrete girders }\end{array}$ \\
\hline & $2 \mathrm{~L}$ & LWC & 1995 & 1,300 & $\begin{array}{l}\text { Reinforced concrete deck on } \\
\text { prestressed concrete girders }\end{array}$ \\
\hline & $3 \mathrm{~N}$ & NWC & 1994 & 6,200 & $\begin{array}{l}\text { Reinforced concrete deck on } \\
\text { prestressed concrete girders }\end{array}$ \\
\hline & $3 \mathrm{~L}$ & LWC & 1994 & 6,200 & $\begin{array}{l}\text { Reinforced concrete deck on } \\
\text { prestressed concrete girders }\end{array}$ \\
\hline & $5 \mathrm{~N}$ & NWC & 1990 & 16,000 & $\begin{array}{l}\text { Reinforced concrete deck on } \\
\text { prestressed concrete girders }\end{array}$ \\
\hline & $5 \mathrm{~L}$ & LWC & 1990 & 16,000 & $\begin{array}{l}\text { Reinforced concrete deck on } \\
\text { prestressed concrete girders }\end{array}$ \\
\hline \multirow[t]{4}{*}{ Piedmont } & $6 \mathrm{~N}$ & NWC & 1998 & 68,000 & $\begin{array}{l}\text { Reinforced concrete deck on } \\
\text { steel plate girders (main spans) }\end{array}$ \\
\hline & $6 \mathrm{~L}$ & LWC & 1999 & 64,000 & $\begin{array}{l}\text { Reinforced concrete deck on } \\
\text { steel I-beams }\end{array}$ \\
\hline & $7 \mathrm{~N}$ & NWC & 1989 & 8,500 & $\begin{array}{l}\text { Reinforced concrete deck (stay- } \\
\text { in-place metal forms at } \\
\text { approach spans) on plate } \\
\text { girders and continuous plate } \\
\text { girders (main spans) }\end{array}$ \\
\hline & $7 \mathrm{~L}$ & LWC & 1992 & 8,000 & $\begin{array}{l}\text { Reinforced concrete deck on } \\
\text { continuous steel I-beams } \\
\text { (approach spans) }\end{array}$ \\
\hline \multirow[t]{4}{*}{ Mountains } & $8 \mathrm{~N}$ & NWC & 2000 & 14,000 & $\begin{array}{l}\text { Reinforced concrete deck (stay- } \\
\text { in-place metal forms) on } \\
\text { prestressed concrete girders }\end{array}$ \\
\hline & $8 \mathrm{~L}$ & LWC & 1999 & 14,000 & $\begin{array}{l}\text { Reinforced concrete deck (stay- } \\
\text { in-place metal forms) on steel } \\
\text { I-beams (widened) }\end{array}$ \\
\hline & $9 \mathrm{~N}$ & NWC & 2000 & 14,000 & $\begin{array}{c}\text { Reinforced concrete deck (stay- } \\
\text { in-place metal forms) on } \\
\text { prestressed concrete girders }\end{array}$ \\
\hline & 9L & LWC & 1996 & 16,000 & $\begin{array}{l}\text { Reinforced concrete deck (stay- } \\
\text { in-place metal forms) on steel } \\
\text { I-beams (widened) }\end{array}$ \\
\hline
\end{tabular}

Unfortunately after performing field work on bridge decks $4 \mathrm{~N}$ and $4 \mathrm{~L}$, it was determined that $4 \mathrm{~L}$ was incorrectly identified in NCDOT records as a lightweight concrete bridge deck. In following with the intent of this study (to compare lightweight concrete bridge decks and normalweight concrete bridge decks of similar age, exposure, and traffic loading), results from bridge decks $4 \mathrm{~N}$ and $4 \mathrm{~L}$ were not included in analysis.

find a companion normalweight bridge deck with a similar superstructure, that also closely matched in age, traffic, and geographic region. To facilitate ease of identification of pairs of decks, each bridge deck was given a Pair/ID designation.
For each member of a pair, the normalweight concrete deck was designated as "\#N," while the lightweight concrete deck was designated as "\#L." In Table 1, for "Type of Deck," normalweight concrete decks are also listed as "NWC," 
while lightweight decks are listed as "LWC." It is of note that pairs $2 \mathrm{~N} / 2 \mathrm{~L}, 3 \mathrm{~N} / 3 \mathrm{~L}$, and $5 \mathrm{~N} / 5 \mathrm{~L}$, the normalweight and lightweight decks are on different spans of the same bridge.

For each bridge, information provided on bridge inspection reports and drawings, such as span lengths, lane widths, shoulder width and other geometric data was used to assist in generation of a digital drawing of a portion (or, in some cases, all) of the bridge. For each bridge deck, a sample section was identified for field evaluation and testing. To facilitate completion of fieldwork within the allowable lane closure hours in one working day, sections typically ranged from approximately 42-86 meters (140-280 feet) in length. For smaller bridges (less than 100 feet), the sample section included the full length of the bridge deck. Thru-traffic needed to be accommodated during the work, so sample sections typically consisted of the shoulder and right-hand travel lane. When the total bridge length was longer than the sample section, effort was made to ensure that distress visually evident in the sample section was typical of the distress visually evident on other parts of the bridge deck. The surveys were performed on the top surface of each bridge deck, during dry conditions, and each visual survey was performed by the same individual in order to maintain consistency. Visual survey observations were noted on a field sketch that was drawn to scale printed out prior to visiting the site.

Specific distresses identified during the visual survey included longitudinal cracks, transverse cracks, surface cracking, delaminations, and other surface distress. Consistent with the field inspection protocols of many agencies, cracks were only noted if they were visible by viewing the deck in a position bent no lower than the waist. If a crack was observed, the continuation of a crack was added to the field sketch if the observer could follow it by bending no lower than the waist. Field observation techniques utilized were similar to those presented in Darwin et al. (2004). In an effort to assist with judging the relative condition of bridge decks based on visual distresses, severity levels were assigned to observed pattern cracking (low, moderate, and high severity). Pattern cracking denoted as low severity was typically only faintly visible during the observations, comprised of fine hairline cracks, as defined in ACI 201.1 (ACI 2008). Pattern cracking denoted as moderate severity was easily visible during the visual survey, and the widths of the cracks were larger than what would be considered hairline by ACI 201.1 (ACI 2008). Observations recorded on field sketches were subsequently transferred into AutoCad drawings. A typical visual survey sketch, as transferred into the digital drawing, is shown in Fig. 1.

Cores removed from each deck confirmed the presence of lightweight or normalweight coarse aggregate. Petrographic examination confirmed that the coarse aggregates for lightweight concrete mixtures were entirely lightweight aggregate (not partially blended with normalweight coarse aggregate). Petrographic examination also revealed that the lightweight aggregate utilized in each of the bridge decks was an expanded shale obtained from a local source. Typically, information on the mixture proportions, cement composition, placement conditions, and fresh and hardened concrete test results used on the bridge decks was not available. Therefore, analysis to evaluate the effect of different mixture parameters (such as water content, cement content, admixtures, and mixture components) could not be performed. However, the paired approach to this study allowed direct comparison of decks with similar environmental exposure, traffic, and age. Additionally, it can be assumed that the concrete comprising both types of decks met the requirements of the state highway agency's standards and specifications for concrete used in bridge decks, as applicable at the time of construction. For bridge decks, this is typically designated as Class AA concrete, with a minimum 28-day $\mathrm{f}^{\prime}{ }_{\mathrm{c}}$ of $31 \mathrm{MPa}$ (4500 psi) with a maximum $\mathrm{w} / \mathrm{cm}$ of 0.426 (angular aggregate) and a cement content ranging from 379 to $424 \mathrm{~kg} / \mathrm{m}^{3}$ (639 to $715 \mathrm{pcy}$ ). It is very important to note that adequate durability performance incorporates far more characteristics than resistance to cracking, and durability assessment should include resistance to weathering, chemical attack, abrasion, and other service conditions. Therefore, in addition to visual surveys to quantify extent of cracking, additional field and laboratory testing to evaluate durability performance was performed. Field tests included air permeability, surface resistivity, and rebound hammer. Sampling of drilled powders were obtained and tested to determine chloride content. Drilled cores were removed and returned to the laboratory for testing for compressive strength, sorptivity, and rapid chloride ion permeability. Additionally, petrographic examination was performed on cores from each deck to evaluate the characteristics of cracking. For additional information on laboratory testing portions of this research program, the reader is referred to Cavalline et al. (2013). Other results will be published in separate publications.

\section{Results and Analysis}

The digital drawings of the visual survey results were used to determine the total survey area and tally the observed distresses. A summary of the bridge age, average daily traffic (ADT), and observed area for each pair of bridges is shown in Table 2. Overall, it can be noted that bridge decks included in this study ranged from 11 to 22 years old at the time of field observations. Of the nine pairs of decks, five differed in age by approximately 1 year or less, facilitating excellent direct comparison from a temporal perspective. The other pairs differed by 2-4 years in age, at most. The ADT for deck pairs were quite similar, with the exception of pair $1 \mathrm{~N} / 1 \mathrm{~L}$. It is noted that this pair had a relatively low ADT.

Using the digitized drawings, crack densities were calculated. For this study, two types of crack densities were calculated. For linear cracking, crack density was quantified in terms of length of crack per unit area (linear meters of cracking per square meter of bridge deck). The crack density of pattern cracking was quantified in terms of area of pattern cracking per unit area of bridge deck observed (square 


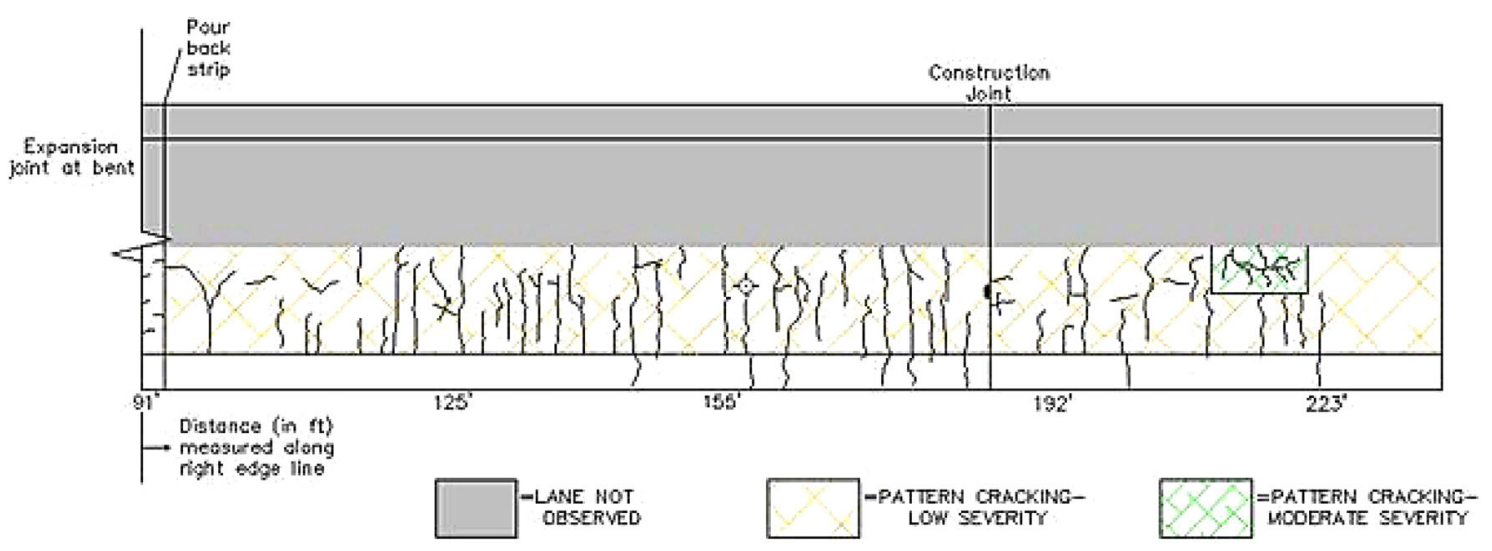

Fig. 1 Typical bridge visual survey showing cracks observed.

Table 2 Bridge characteristics and observed area.

\begin{tabular}{|c|c|c|c|c|c|c|}
\hline \multirow[t]{2}{*}{ Bridge pair ID } & \multicolumn{2}{|c|}{ Age (years) at time of field observation } & \multicolumn{2}{|c|}{$\mathrm{ADT}$} & \multicolumn{2}{|c|}{ Observed area $\left(\mathrm{m}^{2}\right)$} \\
\hline & NWC & LWC & NWC & LWC & NWC & LWC \\
\hline 1 & 13 & 11 & 4,300 & 9,400 & 107 & 492 \\
\hline 2 & 16 & 16 & 1,300 & 1,300 & 418 & 418 \\
\hline 3 & 17 & 17 & 6,200 & 6,200 & 321 & 142 \\
\hline 5 & 21 & 21 & 16,000 & 16,000 & 492 & 431 \\
\hline 6 & 13 & 12 & 68,000 & 64,000 & 884 & 821 \\
\hline 7 & 22 & 19 & 8,500 & 8,000 & 357 & 290 \\
\hline 8 & 11 & 12 & 14,000 & 14,000 & 585 & 289 \\
\hline 9 & 11 & 15 & 14,000 & 16,000 & 435 & 562 \\
\hline
\end{tabular}

meters of pattern cracking per square meter of bridge deck). A summary of transverse, longitudinal, and pattern cracking densities is shown in Table 3 .

As can be seen in Table 3 (and will be further illustrated in subsequent figures), a distinct trend in the cracking performance of the paired lightweight bridge decks and normalweight bridge decks is not readily evident. In some pairs, the lightweight concrete deck exhibited higher crack densities than the normalweight deck. In other pairs, the normalweight deck exhibited higher crack densities than the lightweight deck. Further analysis to identify trends in cracking performance associated with geographic location, traffic, and age is presented in the following sections, along with visual comparisons to support this finding.

Overall, cracking densities tended to be in the same range as those reported for bridge decks of similar ages in the study by Darwin et al. (2004). It was of interest that several decks exhibited minimal (or no) cracking, despite being in service for over 10 years. Lightweight bridge deck $2 \mathrm{~L}$ and normalweight bridge deck $2 \mathrm{~N}$, on the same bridge, exhibited virtually no cracking after 16 years of service in a coastal environment. The low traffic on this pair of bridges alludes to the potential role of traffic-induced stress on cracking, as well as the ability of these particular concrete mixtures to perform well in a coastal environment. The most extensive pattern cracking was observed in bridge decks in the Piedmont region. It is of note that these decks included the oldest pair $(7 \mathrm{~N} / 7 \mathrm{~L})$ and the pair experiencing the highest traffic volume $(6 \mathrm{~N} / 6 \mathrm{~L})$.

\subsection{Comparison of Pairs of Bridge Decks and Influence of Geographic Region}

From the data shown in Table 1, bar charts were prepared to facilitate comparison of cracking of the lightweight and normalweight bridge deck included in each pair. Pairs of bridge decks were also grouped by region to provide additional insight on the possible influence of geographic region on performance. As can be seen in Fig. 2, most coastal bridges exhibited very little transverse cracking. This could be a function of the relatively low traffic generally served by these bridges, the concretes mixture utilized, design considerations, construction practices, or some other factor. As indicated previously, bridges in the Piedmont and Mountain regions exhibited more transverse cracking than the Coastal bridges. However, a distinct trend showing improved cracking resistance of lightweight bridge decks was not noted for transverse cracking.

Longitudinal cracking was observed in a number of bridges, with computed crack densities shown in Fig. 3. A relatively high density of longitudinal cracking was observed in one lightweight coastal bridge deck and one normalweight bridge deck in the mountain region of the state included in the study. Similar to a comparison of transverse cracking densities, a distinct trend showing improved performance of 
Table 3 Summary of cracking observed.

\begin{tabular}{|c|c|c|c|c|c|c|c|c|c|c|c|c|}
\hline \multirow[t]{2}{*}{$\begin{array}{l}\text { Bridge } \\
\text { pair ID }\end{array}$} & \multicolumn{2}{|c|}{$\begin{array}{c}\text { Transverse cracking } \\
\text { density } \\
\left(\mathrm{m} / \mathrm{m}^{2} \text { of deck }\right)\end{array}$} & \multicolumn{2}{|c|}{$\begin{array}{l}\text { Longitudinal } \\
\text { cracking density } \\
\left(\mathrm{m} / \mathrm{m}^{2} \text { of deck }\right)\end{array}$} & \multicolumn{2}{|c|}{$\begin{array}{c}\text { Total linear cracking } \\
\text { density } \\
\left(\mathrm{m} / \mathrm{m}^{2} \text { of deck }\right)\end{array}$} & \multicolumn{2}{|c|}{$\begin{array}{c}\text { Moderate severity } \\
\text { pattern cracking } \\
\text { density } \\
\left(\mathrm{m}^{2} / \mathrm{m}^{2} \text { of deck }\right)\end{array}$} & \multicolumn{2}{|c|}{$\begin{array}{l}\text { Low severity pattern } \\
\text { cracking density } \\
\left(\mathrm{m}^{2} / \mathrm{m}^{2} \text { of deck }\right)\end{array}$} & \multicolumn{2}{|c|}{$\begin{array}{c}\text { Total pattern cracking } \\
\text { density } \\
\left(\mathrm{m}^{2} / \mathrm{m}^{2} \text { of } \text { deck }\right)\end{array}$} \\
\hline & NWC & LWC & NWC & LWC & NWC & LWC & NWC & LWC & NWC & LWC & NWC & LWC \\
\hline 1 & 0.0071 & 0.1192 & 0.0423 & 0.0246 & 0.0494 & 0.1438 & 0.000 & 0.000 & 0.571 & 0.679 & 0.571 & 0.679 \\
\hline 2 & 0.0000 & 0.0000 & 0.0000 & 0.0016 & 0.0000 & 0.0016 & 0.000 & 0.000 & 0.000 & 0.000 & 0.000 & 0.000 \\
\hline 3 & 0.0075 & 0.0356 & 0.0034 & 0.7031 & 0.0109 & 0.7387 & 0.000 & 0.000 & 0.000 & 0.000 & 0.000 & 0.000 \\
\hline 5 & 0.0654 & 0.0044 & 0.0101 & 0.0596 & 0.0755 & 0.0640 & 0.000 & 0.000 & 0.750 & 0.000 & 0.750 & 0.000 \\
\hline 6 & 0.0374 & 0.0211 & 0.0000 & 0.0056 & 0.0374 & 0.0266 & 0.329 & 0.311 & 0.571 & 0.582 & 0.900 & 0.893 \\
\hline 7 & 0.4263 & 1.3913 & 0.0690 & 0.0083 & 0.4953 & 1.3996 & 0.013 & 0.000 & 0.737 & 0.857 & 0.750 & 0.857 \\
\hline 8 & 0.4820 & 0.0000 & 0.6231 & 0.0896 & 1.1051 & 0.0896 & 0.000 & 0.000 & 0.000 & 0.571 & 0.000 & 0.571 \\
\hline 9 & 0.0791 & 0.3507 & 0.0697 & 0.0091 & 0.1488 & 0.3598 & 0.000 & 0.000 & 0.000 & 0.000 & 0.000 & 0.000 \\
\hline
\end{tabular}

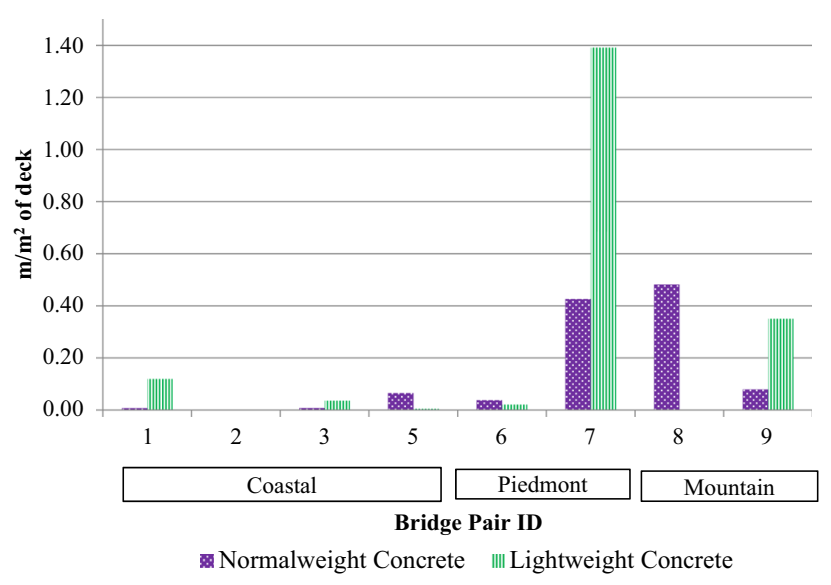

Fig. 2 Transverse cracking density for bridge deck pairs.

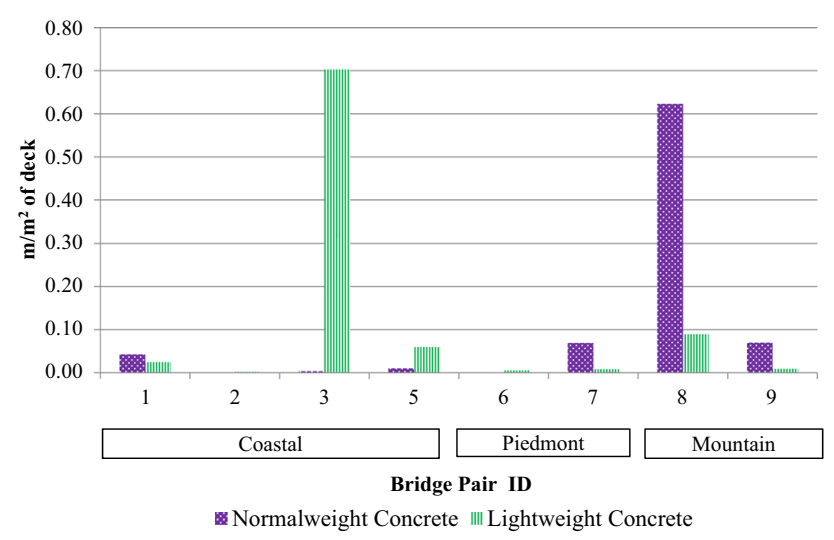

Fig. 3 Longitudinal cracking density for bridge deck pairs.

lightweight concrete bridge decks was not observed when comparing longitudinal cracking densities. However, for both pairs of bridge decks in the mountains, the lightweight bridge decks exhibited significantly lower densities of longitudinal cracking.

Pattern cracking was observed on a number of bridge decks included in the study. As shown in Table 3, the most severe pattern cracking (judged to be moderate severity) was

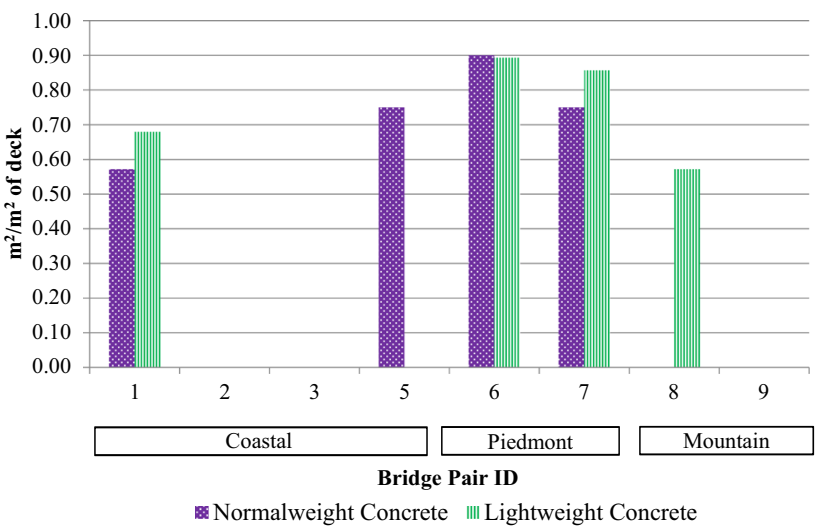

Fig. 4 Pattern cracking density for bridge deck pairs.

observed in bridge decks $6 \mathrm{~N}$ and 6L. As mentioned previously, these bridge decks, located on an interstate in the Piedmont region, had the highest traffic loading (ADT of 68,000 and 64,000 respectively). This pattern cracking could have initiated due to materials related issues, but were likely exacerbated due to traffic loads. An analysis of the relationship between ADT on observed cracking is presented subsequently in this paper.

Overall densities of pattern cracking were computed using the observed areas of both low and moderate severity pattern cracking. The crack densities for all observed pattern cracking (sum of both low and moderate severity) are shown in Fig. 4. It can be seen that for three of the eight bridge deck pairs $(1 \mathrm{~N} / 1 \mathrm{~L}, 6 \mathrm{~N} / 6 \mathrm{~L}$, and $7 \mathrm{~N} / 7 \mathrm{~L}$, the pattern cracking densities are very similar in both the lightweight and normalweight decks. Results were mixed for two other pairs of bridge decks. Bridge decks $5 \mathrm{~N}$ and $5 \mathrm{~L}$ are located on the same coastal bridge. The normalweight deck $(5 \mathrm{~N})$ exhibited pattern cracking while the lightweight deck $(5 \mathrm{~L})$ did not. Alternatively, for mountain bridges $8 \mathrm{~N}$ and $8 \mathrm{~L}$, the lightweight bridge deck exhibited cracking while the normalweight bridge deck did not. It is noted, however, that bridge deck pair $8 \mathrm{~L}$ and $8 \mathrm{~N}$ may not be the strongest pairing, because although the ADT and ages of these two bridge 
decks is similar, they are on two different roadways in two separate counties.

\subsection{Influence of Vehicle Traffic}

Crack densities were plotted against ADT to determine if one type of bridge deck (lightweight or normalweight) exhibited better performance under higher traffic volumes. When transverse and longitudinal cracking densities are plotted versus ADT (Figs. 5, 6 respectively), enhanced performance of either type of deck at higher ADTs is not observed. A plot of pattern cracking density versus ADT (Fig. 7) does not clearly reveal an increase in crack density with ADT. This is similar to the findings of earlier studies that reported no relationship between daily bridge traffic and deck cracking tendency. Enhanced performance of either type of deck at higher ADTs is not evident, although a threshold ADT for the enhanced performance of lightweight bridge decks could exist.

Bridge decks included in this study typically had ADT below 20,000. One bridge deck pair included in the study (decks $6 \mathrm{~N}$ and $6 \mathrm{~L}$ located in the Piedmont region) had significantly higher ADT (68,000 and 64,000 respectively). Cracking densities for each of the three types of cracking observed (transverse, longitudinal, and pattern) were similar for the normalweight and lightweight deck in this pair of high-traffic decks. As can be seen in Fig. 5, for bridges with

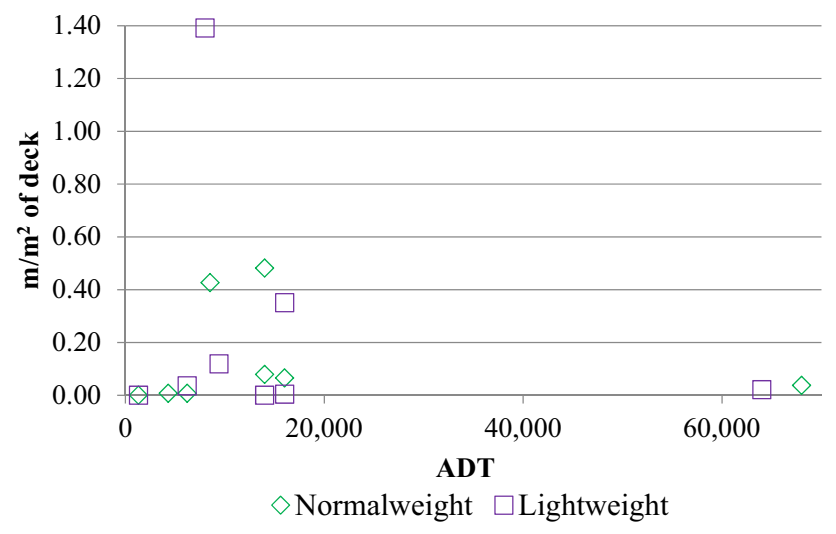

Fig. 5 Transverse cracking versus ADT.

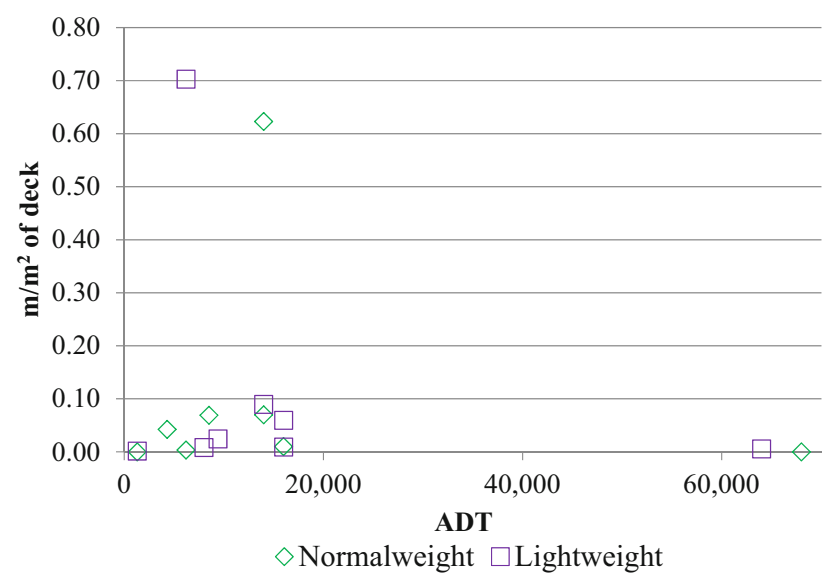

Fig. 6 Longitudinal cracking versus ADT.

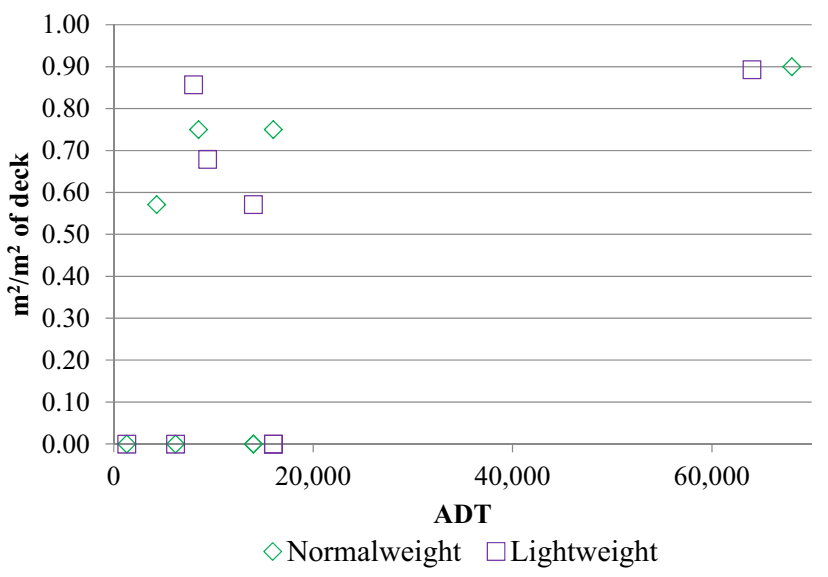

Fig. 7 Pattern cracking versus ADT.

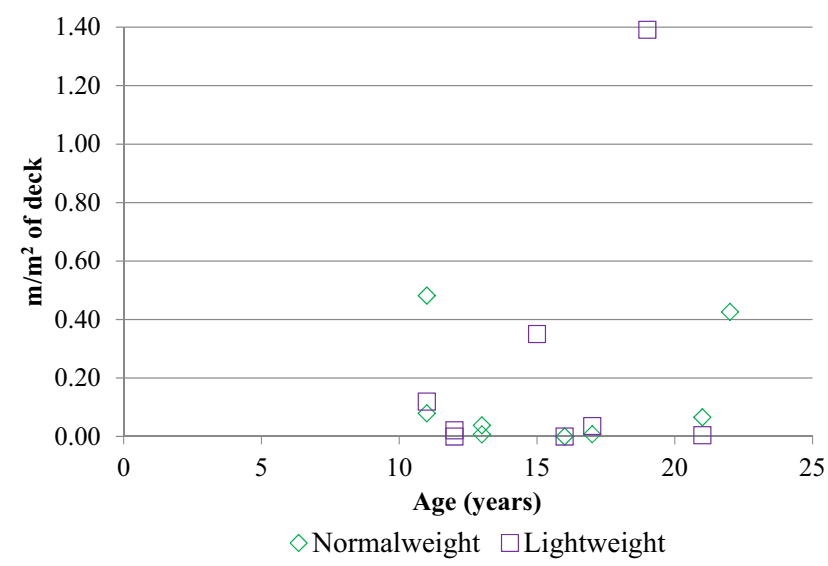

Fig. 8 Transverse cracking density versus bridge deck age.

less than 20,000 ADT (with a few exceptions, bridges 7L and 9L), lightweight bridge decks tended to show lower crack densities at higher ADTs, when the ADT was less than 20,000. Plots of longitudinal cracking density and pattern cracking density versus ADT did not reveal any trends in the performance of either lightweight or normalweight bridge decks for bridges with less than 20,000 ADT.

\subsection{Influence of Age of Bridge Deck}

Crack densities were plotted against bridge deck age in order to determine whether trends in the performance of the different types of bridge decks over time could be identified (Figs. 8, 9, 10). Lower cracking densities of the lightweight decks was not readily evident for the newer bridge decks included in the study (ages 10-15 years) or for the older bridge decks included in the study (ages 15 or more years). It is possible that there has not been ample time for distinct differences in performance between lightweight and normalweight concrete decks included in this study to become evident during field observations. Although this is a positive finding for the sponsoring state agency, this also indicates that a revisit of the decks included in this study would provide more insight into performance differences. The pairs of bridge decks could be revisited at future times to observe and document changes, supplementing findings of this work. 


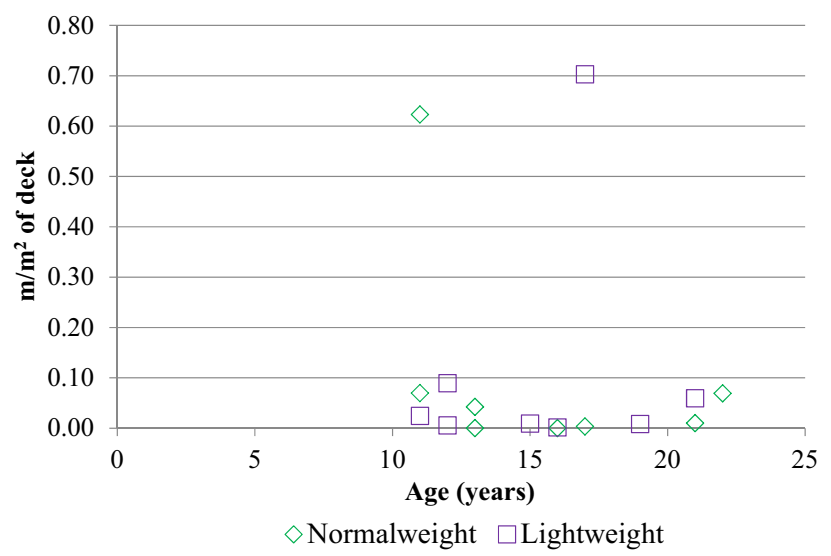

Fig. 9 Longitudinal cracking density versus bridge deck age.

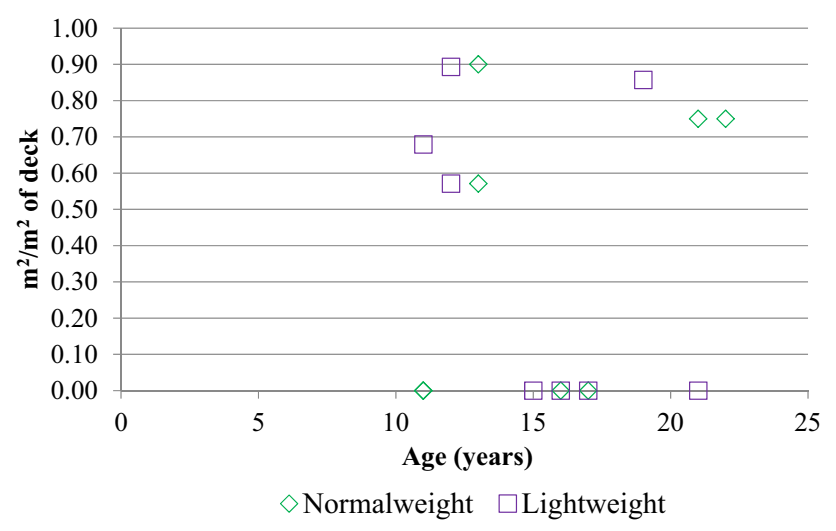

Fig. 10 Pattern cracking versus bridge deck age.

\subsection{Influence of Superstructure Type and Structure Characteristics}

Continuous steel girders have historically been associated with more extensive bridge deck cracking (Krauss and Rogalla 1996), and the propensity of steel girder bridges to exhibit more cracking was found specifically in the state of North Carolina by Cheng and Johnston (1985) and Perfetti et al. (1985). The two bridge decks with continuous span girders (bridge decks $6 \mathrm{~N}$ and $6 \mathrm{~L}$ ) exhibited some of the more extensive pattern cracking and some transverse cracking, and it is possible that some of this cracking could be the result of stresses present in the deck slab due to the continuous steel girders, rather than from effects related to the type of concrete mixture utilized. The most extensive transverse cracking observed on bridge decks included in the study is present on bridge decks $7 \mathrm{~N}$ and $7 \mathrm{~L}$, which are supported by steel plate girders and steel I-beams, respectively.

Transverse cracking on these decks may also be related to structural-related stresses, such as restrained shrinkage effects due to connections on steel girders, negative bending moments over steel supports or other structural-related stresses. These cracks could have also occurred due to loads applied too soon after the deck was constructed, or other reasons. These two bridges are also two of the oldest bridges included in the study, and traffic loads could also play a role in the development of transverse cracks. Bridge decks with stay-in-place metal forms (bridge decks $8 \mathrm{~N} / 8 \mathrm{~L}$ and $9 \mathrm{~N} / 9 \mathrm{~L}$ ) also tended to exhibit more longitudinal and transverse cracking than bridge decks on precast concrete girders and non-continuous steel girders. Stay-in-place metal forms are not typically considered to be bonded to the concrete deck, although some restraint due to partial bonding and friction can be expected. It is interesting to note that although all four of these bridges have stay-in-place forms, they are supported by different types of girders, with bridges $8 \mathrm{~L}$ and $9 \mathrm{~L}$ on widened steel I-beams, while bridges $8 \mathrm{~N}$ and $9 \mathrm{~N}$ have stayin-place forms on prestressed concrete girders. Some of the cracking observed on the bridge decks $8 \mathrm{~N}, 8 \mathrm{~L}, 9 \mathrm{~N}$, and $9 \mathrm{~L}$ may also be attributable to the superstructure design, rather than from concrete materials-related causes. Other bridge decks exhibiting transverse cracks (albeit to a lesser extent than in bridge decks $6 \mathrm{~N}, 6 \mathrm{~L}, 7 \mathrm{~N}, 7 \mathrm{~L}, 8 \mathrm{~N}, 8 \mathrm{~L}, 9 \mathrm{~N}$, and $9 \mathrm{~L}$ ), include bridge decks $1 \mathrm{~L}, 3 \mathrm{~N}$, and $5 \mathrm{~N}$.

\subsection{Statistical Analysis}

Ultimately, cracking of bridge decks occurs as a result of the design characteristics, materials used, mixture performance, construction practice, or some combination of these factors. To confirm general trends observed from direct pairwise comparisons, and to further explore the role of type of concrete bridge decks and other factors such as region and structural characteristics on observed cracking, covariance analysis (ANCOVA) with multiple covariates was performed. ANCOVA analysis (analysis of covariance) "is an extension of analysis of variance in which main effects and interactions of independent variables are assessed after dependent variable scores are adjusted for differences associated with one or more covariates (Tabachnick and Fidell 2007).” Multiple covariate analysis (or multiple ANCOVA) allows for multiple covariates (e.g. age and ADT) to be included in one analysis of covariance, with the adjusted treatment mean differences then interpreted as being independent of all variables included as covariates (Huitema 1980). Statistical operations for ANCOVA are similar to ANOVA; however, the regression of the covariates on the dependent variables is estimated first. Subsequently, the "dependent variable scores and means are adjusted to remove the linear effects of the covariates before analysis of variance is performed on these adjusted values (Tabachnick and Fidell 2007). The strength of use of ANCOVA analysis for this work is the accommodation of the effects of age and ADT (continuous variables) on observed cracking, allowing the influence of structural factors, such as type of concrete deck, on cracking to be more fully explored. Separate multiple ANCOVA analyses were performed for each response (dependent) variable of transverse cracking, longitudinal cracking, and total pattern cracking using the General Linear Model fitting tools in Minitab 17 statistical analysis software. Independent variables treated categorically as factors included deck type (LWC or NWC), region (Coastal, Piedmont, and Mountain), girder type (prestressed concrete girders or steel girders), stay-in-place forms (not present or present). ADT and age were treated as covariates. 
Table 4 Summary of ANCOVA analyses.

\begin{tabular}{|c|c|c|c|c|c|}
\hline Source & df & $\begin{array}{c}\text { Adjusted sum of } \\
\text { squares }\end{array}$ & Adjusted mean square & F-value & $\mathrm{p}$ value \\
\hline \multicolumn{6}{|c|}{ Analysis of covariance for transverse cracking } \\
\hline Age & 1 & 0.01007 & 0.01007 & 0.015 & 0.707 \\
\hline ADT & 1 & 0.45093 & 0.45093 & 6.77 & 0.029 \\
\hline Region & 2 & 0.64760 & 0.32380 & 4.86 & 0.037 \\
\hline Deck type & 1 & 0.09684 & 0.09684 & 1.45 & 0.259 \\
\hline Girder type & 1 & 0.06124 & 0.06124 & 0.92 & 0.363 \\
\hline Error & 9 & 0.59949 & 0.06661 & & \\
\hline Total & 15 & 1.92792 & & & \\
\hline \multicolumn{6}{|c|}{ Analysis of covariance for longitudinal cracking } \\
\hline Age & 1 & 0.004201 & 0.004201 & 0.07 & 0.795 \\
\hline ADT & 1 & 0.000038 & 0.000038 & 0.00 & 0.980 \\
\hline Region & 2 & 0.117831 & 0.058916 & 1.01 & 0.403 \\
\hline Deck type & 1 & 0.041457 & 0.041457 & 0.71 & 0.422 \\
\hline Girder type & 1 & 0.128559 & 0.128559 & 2.20 & 0.172 \\
\hline Error & 9 & 0.526219 & 0.058469 & & \\
\hline Total & 15 & 0.721801 & & & \\
\hline \multicolumn{6}{|c|}{ Analysis of covariance for pattern cracking } \\
\hline Age & 1 & 0.09417 & 0.094167 & 0.96 & 0.352 \\
\hline ADT & 1 & 0.00001 & 0.000007 & 0.00 & 0.993 \\
\hline Region & 2 & 0.48023 & 0.240114 & 2.46 & 0.141 \\
\hline Deck type & 1 & 0.04134 & 0.041338 & 0.42 & 0.531 \\
\hline Girder type & 1 & 0.15677 & 0.156769 & 1.61 & 0.237 \\
\hline Error & 9 & 0.87845 & 0.097605 & & \\
\hline Total & 15 & 2.35301 & & & \\
\hline
\end{tabular}

A summary of the results of the multiple ANCOVA analyses is presented in Table 4. For each of the three analyses, stay-in-place forms was identified as a predictor variable highly correlated with other predictor variables, with a variance inflation factor (VIF) much greater than 10 . "Stay-in-place forms" was therefore removed from the analysis by the software's general linear model algorithm. The VIF for each of the other factors and covariates was less than 10 (with most less than 5), indicating that multicollinearity did not influence the regression results.

Multiple ANCOVA analysis for transverse cracking indicated that after adjustment of the model for covariates of ADT and age, the only statistically significant factor was region ( $\mathrm{p}$ value $<0.05$ ) at $\alpha=0.05$. The type of concrete deck (LWC or NWC) and girder type were not significant, as suspected from observations from the general trends shown in previous comparison plots. Overall, the model produced by the ANCOVA analysis for transverse cracking had an $\mathrm{R}^{2}$ of $68.9 \%$, indicating that almost $70 \%$ of the observed variation could be explained by the variables included in the analysis. Model coefficients indicated a positive correlation with age, but surprisingly, a negative correlation with ADT. The negative correlation with ADT was likely influenced by the bridge deck pair $6 \mathrm{~N}$ and $6 \mathrm{~L}$ located in the Piedmont region), which had significantly higher ADT than other bridges, but relatively low cracking.

Results of the multiple ANCOVA analysis for longitudinal cracking resulted in a poorly fit model $\left(\mathrm{R}^{2}=27.10 \%\right)$, with no factors or covariates showing statistically significant effects at $\alpha=0.05$ ( $\mathrm{p}$ for each $>0.05$ ). The model produced by multiple ANCOVA analysis for total pattern cracking provided a better fit $\left(\mathrm{R}^{2}=62.67 \%\right)$, but again, no factors or covariates showed statistically significant effects ( $\mathrm{p}$ for each $>0.05$ ).

\section{Conclusions and Discussion}

Based on the analysis presented above, the following conclusions were made: 
- Overall, a distinct difference between the overall fieldobserved cracking of the lightweight bridge decks and normalweight bridge decks included in this study was not readily evident through direct paired comparison or though statistical analysis. This finding, based on field observations, differs from those of several studies that have indicated that use of lightweight concrete can reduce cracking.

- Statistical analysis using ANCOVA to adjust the regression model for traffic and age did not find deck type or girder type a statistically significant factor (at $\alpha=0.05$ ) in transverse, longitudinal, or pattern cracking.

- The region in which a bridge is located was identified as a significant predictor of transverse cracking at $\alpha=0.05$, with Coastal region bridges exhibiting less transverse cracking than bridges in the Piedmont and Mountain regions of the state. This may be the effect of some special considerations (some related to mixture proportioning) provided to bridges in areas of the Coastal region identified as susceptible to high corrosion.

It is important to note that none of the lightweight decks were specifically designed for internal curing, which has been shown to enhance the durability performance of concrete bridge decks (Wolfe 2008; Delatte et al. 2007b; Bentz and Weiss 2011; Barrett et al. 2013). However, since most lightweight bridge decks currently in service are conventional lightweight decks (containing lightweight coarse aggregate), this study provides useful insight for highway agencies into the relative performance of lightweight decks from a cracking perspective. In particular, this finding was useful to the sponsoring agency to support design decisions and may be useful for forecasting required maintenance, repair, and replacement projects.

Bridge decks included in this study were typically 10-20 years of age at the time of the site visit, which can be up to $1 / 3$ of the design life of the structure. It is possible that that there has not been ample time for distinct differences in performance between lightweight and normalweight concrete decks included in this study to become evident during field observations. Over time, the differences in cracking distress between the lightweight decks and normalweight decks may become more pronounced, and differences in the extent and severity of cracks between bridge deck pairs could be observed in future visual surveys.

\section{Acknowledgements}

The research presented in this paper is part of the research project RP 2011-06 sponsored by the North Carolina Department of Transportation. The financial support provided by this grant is greatly appreciated. The contents of this paper reflect the views of the authors and not necessarily the views of the NCDOT. The authors are responsible for the accuracy of the data presented herein. Additionally, this paper does not constitute a standard, specification, or regulation and does not necessarily reflect official policies of NCDOT. The authors would like to thank NCDOT personnel Dan Holderman, Greg Perfetti, and the project Technical Advisory Committee. Volkert Engineering provided assistance with fieldwork.

\section{Open Access}

This article is distributed under the terms of the Creative Commons Attribution 4.0 International License ( http://creativecommons.org/licenses/by/4.0/), which permits unrestricted use, distribution, and reproduction in any medium, provided you give appropriate credit to the original author(s) and the source, provide a link to the Creative Commons license, and indicate if changes were made.

\section{References}

American Concrete Institute (ACI). (2008). Guide for conducting a visual inspection of concrete in service. ACI Committee Report 201.1R-08.

Barrett T. J., Miller, A., \& Weiss, J. (2013). Documentation of the INDOT experience and construction of the bridge decks containing internal curing in 2013. Technical Report SPR 3752. Joint Transportation Research Program, Indiana Department of Transportation and Purdue University, West Lafayette, IN.

Bentur, A., Igarashi, S.-I., \& Kovler, K. (2001). Prevention of autogenous shrinkage in high strength concrete by internal curing using wet lightweight aggregates. Cement and Concrete Research, 31(11), 1587-1591.

Bentz D. P., \& Weiss W. J. (2011). Internal curing: A 2010 stateof-the-art review. National Institute of Standards and Technology Report NISTIR 7765.

Cady, P. D., \& Carrier, R. E. (1971). Final report on durability of bridge deck concrete: Part 1: Effect of construction practice on durability. PennDOT Contract No. 31057-H. University Park, PA: Pennsylvania State University.

Cady, P. D., Carrier, R. E., Bkar, T., \& Theisen, J. C. (1971). Final report on durability of bridge deck concrete: Part 3: Condition of 249 four year old bridge decks. PennDOT Contract No. 31057-H. University Park, PA: Pennsylvania State University.

Cavalline, T., Kitts, A., \& Calamusa, J. (2013). Durability of lightweight concrete bridge decks - field evaluation. Final Report, North Carolina Department of Transportation Research Project No. 2011-06. Report No. FHWA/NC/2011-06.

Chariton, T., \& Weiss, W.J. (2002). Using acoustic emission to monitor damage development in mortars restrained from volumetric changes. Concrete: Material science to application, a tribute to Surendra P. Shah, SP-206, (pp 205-219). American Concrete Institute, Farmington Hills, MI.

Cheng, T. T.-H. \& Johnston, D. W. (1985). Incidence assessment of transverse cracking in concrete bridge decks: Construction and material considerations, Vol. 1. Report 
No. FHWA/NC/85-002, North Carolina State University, Raleigh, NC.

Chini, A. R., Muszynski, L. C. \& Hicks, J. (2003). Determination of acceptance permeability characteristics for performance-related specifications for portland cement concrete. Report submitted to Florida Department of Transportation, July 11, 2003.

Crowl, D., \& Sutak, M. (2002). A survey of high performance concrete bridge decks, Vol. IV. Ohio Department of Transportation District 12, Garfield Heights.

Darwin, D., Browning, J., \& Lindquist, W. D. (2004). Control of cracking in bridge decks: Observations from the field. Cement, Concrete and Aggregates, 26(2), 148-154.

Delatte, N., Crowl, D., \& Mack, E. (2007a). Reducing cracking of high performance concrete bridge decks. In Proceedings of Transportation Research Board 2007 Annual Meeting.

Delatte, N., Mack, E., \& Cleary, J. (2007b). Evaluation of high absorptive materials to improve internal curing of low permeability concrete. FHWA Report No. FHWA/OH2007/06. Washington, DC: Federal Highway Administration.

ElSafty, A., \& Abdel-Mohti, A. (2013). Investigation of likelihood of cracking in reinforced concrete bridge decks. International Journal of Concrete Structures and Materials, 7(1), 79-93.

Geiker, M. R., Bentz, D. P., \& Jensen, O .M. (2004). Mitigating autogenous shrinkage by internal curing. High-performance structural lightweight concrete. Proceedings of ACI fall convention, 2004.

Guthrie, W. S., \& Yaede, J. M. (2013). Internal Curing of Concrete Bridge Decks in Utah: Preliminary Evaluation. In Proceedings of the 92nd annual meeting of the Transportation Research Board, Washington, DC.

Hadidi, R., \& Saadeghvaziri, M. A. (2005). Transverse cracking of concrete bridge decks: State-of-the-art. Journal of Bridge Engineering, 10(5), 503-510.

Hammer, T. A., Bjontegaard, O., \& Sellevold, E. J. (2004). Internal curing-Role of absorbed water in aggregate. High-performance structural lightweight concrete. Proceedings of American Concrete Institute Fall Convention, 2004.

Harmon, K. S. (2005). Recent research projects to investigate mechanical properties of high-performance lightweight concrete. Seventh international symposium on the utilization of high strength/high-performance concrete, American Concrete Institute, MI.

Huitema, B. E. (1980). The analysis of covariance and alternatives. Hoboken: Wiley.

Issa, M. (1999). Investigation of cracking in concrete bridge decks at early ages. Journal of Bridge Engineering, 4(2), 116-124.

Jones, W. A., House, M. W., \& Weiss, W. J. (2014). Internal curing of high performance concrete using lightweight aggregates and other techniques. Final Report, Colorado Department of Transportation, CDOT-2014-3, Feb 2014.

Krauss, P. D., \& Rogalla, E. A. (1996). Transverse cracking in newly constructed bridge decks. National Cooperative
Highway Research Program Report 380. Washington, DC: Transportation Research Board.

McKeel, W. T. (1985). Evaluation of deck durability on continuous beam highway bridges. Report No. VHTRC 85-R32, Virginia Highway and Transportation Research Council, Charlottesville, VA.

Neville, A. M. (1995). Properties of concrete (4th ed.). New York: Pearson Education.

Ozyildirim, C. (2008). Durability of structural lightweight concrete. 2008 Concrete Bridge Conference, Federal Highway Administration, National Concrete Bridge Council, Missouri Department of Transportation, American Concrete Institute.

Perfetti, G. R., Johnston, D. W., \& Bingham, W .L. (1985). Incidence assessment of transverse cracking in concrete bridge decks: Structural considerations, Vol. 2. Report No. FHWA/NC/8802, North Carolina State University, Raleigh, NC.

Ramirez, J., Olek, J., Rolle, E., \& Malone, B. (2000). Performance of bridge decks and girders with lightweight aggregate concrete. Report FHWA/IN/JTRP-98/17, Joint Transportation Research Program, Purdue University, West Lafayette, IN.

Reinhardt, H. (2008). Comparative performance tests and validation of NDT methods for concrete testing. Journal of Nondestructive Evaluation, 27(1-3), 59-65.

Russell, H. G., Miller, R. A., Ozyildirim, H. C., \& Tadros, M. K. (2006). Compilation and evaluation of results from highperformance concrete projects, Vol. I: Final report. Federal Highway Administration. Report No. FHWA-HRT-05-056.

Saadeghvaziri, M. A., \& Hadidi, R. (2005). Transverse cracking of concrete bridge decks: effects of design factors. Journal of Bridge Engineering, 10(5), 511-519.

Soltani, A., Harries, K. A., \& Shahrooz, B. M. (2013). Crack opening behavior of concrete reinforced with high strength reinforcing steel. International Journal of Concrete Structures and Materials, 7(4), 253-264.

Sousa, C., Sousa, H., Neves, A. S., \& Figueiras, J. (2012). Numerical evaluaiton of the long-term-behavior of precast continuous bridge decks. Journal of Bridge Engineering, 17(1), 89-96.

Stewart, C. F. \& Gunderson, B. J. (1969). Factors affecting the durability of concrete bridge decks. Interim Report No. 2, Research and Development Section of Bridge Department. Sacramento, CA: California Department of Transportation.

Streeter, D. (2012). Internal curing concrete, New York experience. Presentation at the 91st Annual Meeting of the Transportation Research Board, Washington DC.

Tabachnick, B. G., \& Fidell, L. S. (2007). Using multivariate statistics (5th ed.). New York: Pearson.

Transportation Research Board (TRB). (2006). Basic research and emerging technologies related to Concrete Committee. Control of cracking in concrete: State of the art. Transportation Research Circular E-C107.

Vaysburd, A. M. (1996). Durability of lightweight concrete bridges in severe environments. Concrete International, 18(7), 33-38. 
Weiss, W. J., Yang, W., \& Shah, S. P. (1999). Factors influencing durability and early-age cracking in high strength concrete structures. SP-189-22, high performance concrete: Research to practice (pp 387-409), Farmington Hills, MI.
Wolfe, W. H. (2008). lightweight concrete bridge deck performance in severe climates. In 2008 Concrete Bridge Conference, Federal Highway Administration, National Concrete Bridge Council, Missouri Department of Transportation, American Concrete Institute. 